\title{
AVATI KYRY: O RITUAL KAIOWA DO BATISMO DO MILHO NA RESERVA INDÍGENA DE DOURADOS
}

\section{AVATI KYRY: THE RITUAL KAIOWA OF THE BAPTISM OF THE CORN IN THE INDIGENOUS RESERVATION OF DOURADOS}

Lélio Loureiro da Silva (FETAC-silvalelio@bol.com.br)

\section{RESUMO}

ESTE ARTIGO PRETENDE RELATAR AS MINHAS EXPERIÊNCIAS E OBSERVAÇÕES DO RITUAL KAIOWA DO AVATI KYRY (BATISMO DO MILHO), REALIZADO PELA FAMÍLIA EXTENSA LIDERADA PELO CACIQUE GETÚLIO JUCA DE OLIVEIRA E SUA ESPOSA ALDA DA SILVA, MORADORES DA ALDEIA JAGUAPIRU, LOCALIZADA NA RESERVA INDÍGENA FRANCISCO HORTA BARBOSA, ENTRE OS MUNICÍPIOS DE DOURADOS E ITAPORÃ, NO MATO GROSSO DO SUL, DESTACANDO AS DIVERSAS DIFICULDADES PARA A SUA REALIZAÇÃO E A SUA MANUTENÇÃO CULTURAL, UMA VEZ QUE ESSE IMPORTANTE RITUAL DA COSMOLOGIA KAIOWA É O ÚNICO AINDA PRATICADO POR ESSA ETNIA NO LADO BRASILEIRO DO SEU TERRITÓRIO DE OCUPAÇÃO.

PALAVRAS CHAVE: RITUAL KAIOWA, RESERVA INDÍGENA, BATISMO, MILHO.

\section{ABSTRACT}

THIS ARTICLE INTENDS TO RELATE MY EXPERIENCES AND OBSERVATIONS OF THE KAIOWA RITUAL OF THE AVATI KYRY (BAPTISM OF THE MAIZE), CARRIED OUT BY THE EXTENDED FAMILY LED BY THE CHIEF GETÚLIO JUCA DE OLIVEIRA AND HIS WIFE ALDA DA SILVA, RESIDENTS OF THE JAGUAPIRU VILLAGE, LOCATED IN THE FRANCISCO HORTA INDIGENOUS RESERVE BARBOSA, BETWEEN THE MUNICIPALITIES OF DOURADOS AND ITAPOR Ã IN MATO GROSSO DO SUL, HIGHLIGHTING THE VARIOUS DIFFICULTIES FOR ITS REALIZATION AND ITS CULTURAL MAINTENANCE, SINCE THIS IMPORTANT RITUAL OF KAIOWA COSMOLOGY IS THE ONLY ONE PRACTICED BY THIS ETHNICITY ON THE BRAZILIAN SIDE OF BRAZIL. TERRITORY OF OCCUPATION.

KEY WORDS: KAIOWA RITUAL, INDIGENOUS RESERVE, BAPTISM, MAIZE.

\section{INTRODUÇÃO}

Durante duas décadas de convivência com o grupo familiar kaiowá, liderado pelo cacique Getúlio Juca de Oliveira e sua esposa Alda da Silva, moradores na aldeia Jaguapiru, da Reserva Indígena Francisco Horta Barbosa, mais conhecida como Reserva Indígena de Dourados - RID, formada pelas aldeias Jaguapiru e Bororo, pude participar de vários Avati Kyry (Batismo do Milho), algumas vezes do ritual e em outras somente na sua preparação, e 
presenciar as mais variadas dificuldades para a realização e manutenção desse importante ritual.

Esse ritual é de suma importância sócio-político-cultural para os kaiowa e possui grande influência na formação da sua identidade étnica, sendo o único ainda praticado por essa etnia no Mato Grosso do Sul, já que ele é responsável pelo equilíbrio do cosmos, favorecendo a produção agrícola e o teko (modo de ser) desse povo.

Desta forma, a minha intenção neste artigo é descrever o ritual e a sua importância social e cultural para etnia kaiowa, de forma sucinta, pois há vários autores que já descreveram o mesmo, com ênfase recaindo sobre as minhas percepções das dificuldades encontradas pelo cacique Getúlio e seu grupo familiar, na realização e manutenção do Avati Kyry.

O ritual do Batismo do Milho é dividido em duas partes distintas: a preparação, que envolve o processo ritualístico do plantio e desenvolvimento do milho, bem como a preparação para recepcionar os convidados e a realização do ritual em si. A segunda parte é o ritual, o qual é realizado em duas noites seguidas.

\section{A PREPARAÇÃO}

O ritual do Batismo do Milho ocorre na colheita da safra de verão, entre o final do mês de janeiro e o início de março. Não há uma data específica, pois, depende do ponto de colheita do milho, dando preferência para o período da lua cheia, mas sempre iniciando na sexta-feira.

Porém, a sua preparação começa com o plantio do milho crioulo saboró, o avati moroti (milho branco), considerado sagrado pelos Kaiowa e o principal elemento do ritual. $\mathrm{O}$ processo ritualístico se inicia com os cânticos noturnos, executados pelos Yvyraija (auxiliares do rezador), de preparação para o plantio das sementes. Esses cânticos tem a função de "dar sustentação" ao milho, desde o plantio até a sua colheita, garantindo uma boa produtividade e belas espigas, que serão utilizadas no ritual, no consumo alimentar e preservadas como futuras sementes. Essa manutenção das sementes é fundamental já que essa variedade de milho, segundo Vietta:

O avatí moroti ou milho branco, alimento preferido dos ñandejara (nossos deuses; donos do nosso ser; responsáveis por criar e cuidar do nosso ser) é dado aos Kaiowa e aos Nandeva por Jakaira (dono do ser do milho), e por isso exige uma série de cuidados rituais. A princípio, qualquer produto de uma roça kaiowa e ñandeva prescinde de cuidados deste tipo, para garantir a presença dos jara associados às plantas, afastar as pragas, além de regular o regime de chuvas. Mas, a ligação com 
Jakaira transforma o avatí em um produto especial, exigindo cantos e outros procedimentos rituais durante a preparação do solo e a cada etapa do seu desenvolvimento. Os cantos alegram Jakaira, que vem dançar para que as suas plantas brotem e cresçam sadias. Porém, para que o avatí continue a produzir boas sementes também é preciso que os homens dancem e cantem (VIETTA, 2007: 79).

Ao contrário do que afirmam Ballarini et al. (2012: 7) que essa variedade crioula: “[... está ausente da comunidade Guarani da RID”, em meus vinte anos de trabalho na RID, como professor da Educação de Jovens e Adultos (EJA) e do Ensino Médio, a mesma sempre esteve presente na família extensa do cacique Getúlio, sendo cultivada todos os anos.

A cultura do avatí moroti é considerada sagrada, pois o mesmo é elemento determinante nas cerimônias anuais do batismo do milho, sendo expressamente proibida a sua comercialização e somente permitido a doação para os visitantes mais próximos e queridos pelos anfitriões.

O cultivo do avati moroti exige grande sacrifício do grupo familiar devido à falta de terra para o seu plantio. A RID é considerada uma das maiores em densidade demográfica, com aproximadamente $0,3 \mathrm{ha} /$ família, portanto, essa falta de terra faz com que outras culturas sejam relegadas para a preservação do milho saboró, que já não é encontrado tão facilmente no território kaiowá.

Além da falta de espaço territorial, o cultivo do milho sagrado enfrenta sérias dificuldades: "com o avanço do agronegócio e a introdução de tratos culturais diferenciados o milho (sic), assim, como outras espécies cultivadas nos roçados vem sofrendo processos de hibridização e perda da diversidade genética” (BALLARINI et al., 2012: 6).

Com o plantio realizado e os cuidados no desenvolvimento da planta sendo alcançados, uma vez que durante várias noites serão entoados os mais diversos cânticos que favoreceram a maturação do milho, o grupo familiar se volta para a preparação do ritual e no recebimento dos convidados. A falta de recursos naturais e econômicos obriga o cacique Getúlio e sua esposa a uma peregrinação junto a órgãos governamentais e não governamentais, entidades assistenciais e colaboradores individuais na busca de auxílio (alimentos, materiais de limpeza, transporte, entre outros) para a realização do Avati Kyry.

Essa arrecadação é determinante para o "tamanho" do ritual, ou seja, para a quantidade de convidados e para a fartura de alimentos, já que o "bom viver" se estende para a boa recepção dos convidados, com uma boa alimentação, demonstrando o prestígio e a influência política do anfitrião e o seu grupo familiar. 
Na semana que antecede o início do ritual, a agitação entre os membros da família extensa aumenta, com a realização de vários trabalhos focados na preparação do local onde ocorrerá o Batismo, tais como: a arrumação e limpeza do pátio, construções de abrigos provisórios, consertos na casa de reza, preparo da chicha, entre outros. Esse momento depende muito do que foi arrecadado e do número de convidados que estarão presentes nos dias do ritual.

Durante esses anos de convivência com esse grupo familiar kaiowa presenciei grandes rituais, geralmente esses eram patrocinados pela Fundação Nacional do Índio (FUNAI), Fundação Nacional da Saúde (FUNASA), Secretaria Especial de Saúde Indígena (SESAI), Ministério Público Federal (MPF) e Conselho Indigenista Missionário (CIMI) que aproveitavam a reunião com convidados de várias localidades como aldeia Bororo, Panambizinho, Lagoa Rica, Caarapó, Rancho Jacaré, entre outras para discutir diversas questões nos períodos diurnos já que o ritual se realiza no período noturno, como também pequenos rituais restritos somente a família extensa e poucos convidados locais, como o meu caso, quando o apoio recebido para a realização do Batismo do Milho era pequeno e não daria para receber os convidados pela falta de recursos.

Apesar dessas discrepâncias, desde os primeiros anos de convivência e frequência na casa do cacique Getúlio, constatei que ele nunca deixou de realizar o Avati Kyry em um ano se quer, mesmo nos períodos que não ocorreu qualquer arrecadação houve a realização do ritual de forma restrita aos membros da família extensa.

Mesmo com a superação das dificuldades para a realização do Avati Kyry durante todos esses anos, a sua manutenção, em um futuro próximo, não está totalmente garantida uma vez que o espaço territorial destinado ao plantio do milho, que já é mínimo, tem como perspectiva a sua redução com o aumento populacional e a impossibilidade jurídica de expansão da área que compõe a reserva indígena. Além dessa questão, também há outra relacionada a formação dos ñanderu (rezadores), como veremos no capítulo seguinte.

\section{O RITUAL}

Aqui pretendo fazer um breve relato de como é o ritual do Batismo do Milho e, posteriormente, me ater mais as minhas participações na cerimônia ritualística do Avati Kyry, descrevendo as experiências e observações por mim vivenciadas. 
O processo ritualístico do Batismo do Milho se realiza durante duas noites, na fase da lua cheia, começando ao anoitecer do primeiro dia com os Yvyraija, munidos com seus mbaraka (chocalho), iniciam os cânticos sagrados (rezas), acompanhado de movimentos do corpo para frente e para trás, chamando o Jakaira (Dono do milho), enquanto os anfitriões recepcionam os convidados, sempre cantando acompanhados de seus mbaraka, conduzindo-os para o interior da ogapysy (casa de reza) onde se encontra a vasilha com kaguï (chicha) que será consumida durante o ritual, sendo reabastecida sempre que necessário.

A chicha é uma bebida fermentada sagrada, feita de milho ou cana de açúcar, que é essencial na realização dos rituais kaiowa, sendo que o seu consumo não é utilizado de forma recreativa já que ele está associado a ligação entre os seres terrenos e os celestiais.

Os cânticos continuam no decorrer da noite, revelando a parte mais sagrada do ritual, com as mulheres aderindo ao processo ritualístico de posse dos seus takuapu (bastão de taquara), batendo seco no chão de terra e de tempos em tempos ocorre paradas para o consumo da chicha.

Com a aproximação do amanhecer, as mulheres se encaminham para a roça, onde irão colher as espigas que serão utilizadas no batismo e no preparo de diversos quitutes feitos do milho como por exemplo a pamonha, a sopa, cozido, entre outros, que serão consumidos por todos os presentes.

Nesse interim, o ñanderu (rezador) já iniciou o mborahéi puku (canto comprido) cujos versos, que não se repetem, não podem ser interrompidos depois de iniciada a cerimônia. Com o amanhecer ocorre o batismo e começa a preparação dos quitutes, a cada quitute preparado é apresentado ao ñanderu que irá batizá-lo e, após, consumido pelos presentes, terminando o primeiro dia do ritual.

A segunda noite é dedicada ao jerosy puku (danças longas exclusivas dos homens), embaladas pelo guahu (cantos sócio religiosos) e pelo kotyhu (cantos lúdicos), onde os homens dançam de mãos dadas, formando um círculo e batendo os pés fortemente no chão. $\mathrm{O}$ jerosy puku é alternado com o jerosy mbyky (reza curta), onde as mulheres passam a dominar os procedimentos ritualísticos. Nessa noite os mbaraka e takuapu não são utilizados, mas o Kaguï é consumido em grandes quantidades: "pois enquanto houver kãgui há kotyhu" (VIETTA, 2007: 80). 
Nessa última noite, os convidados não indígenas podem participar de todas as danças e, entre várias gargalhadas, dividir a alegria de mais um ritual realizado com sucesso a Jakaira, que feliz proporcionará fartura de alimentos aos kaiowa.

Ao amanhecer os últimos cânticos são entoados e o ritual do Avati Kyry se encerra pois: “[... a esta altura Jakaira já retornou aos patamares Celestes, onde permanece até o próximo período de chuvas, quando se inicia um novo plantio de avatí moroti, e mais uma vez homens e deuses tem motivos para cantar e dançar (VIETTA, 2007: 81).

Ao contrário do que afirmam Ballarini et al (2012: 9): “o batismo do milho é uma prática que atravessou gerações e atualmente permanece viva no imaginário dos que quando crianças puderam presenciar e viver um ritual hoje não mais praticado entre os Guarani da RID”. O mesmo, nesses vinte anos de convívio com o cacique Getúlio e seus familiares, nunca deixou de ser realizado por esse grupo familiar e, neste ano de 2018, como sempre ocorreu, foi realizado no mês de fevereiro e em setembro iniciou-se o plantio do avati moroti e a preparação para o Batismo na colheita da safra de verão.

Desde quando comecei a trabalhar na RID, no início de 1999, e da convivência com a família extensa do cacique Getúlio, participei por volta de oito avati kyry, que relatarei a seguir, e pude presenciar diversas situações que colocaram em risco a realização ou complementação do ritual.

A minha primeira participação no Avati kyry foi marcada pela inexperiência e pelo desconhecimento do modo de ser kaiowa e do processo ritualístico. Nessa época trabalhava na escola Tengatui Marangatu, localizada na aldeia Jaguapiru, como professor da EJA (Educação de Jovens e Adultos) no período noturno e só me dirigi ao local do ritual depois do encerramento das aulas, por volta das $21 \mathrm{~h}$.

Quando cheguei, fui encaminhado pelos yvyraija até a chicha e o altar, acompanhado dos cânticos, tanto o da recepção como o do ritual, que a essa altura já estava em andamento. O ritual estava sendo realizado no pátio da casa do cacique Getúlio e era restrito a família extensa e a poucos convidados da própria aldeia e da aldeia Bororó, que também compõe a RID.

A realização do ritual fora da ogapysy só é realizado pela falta da mesma. A casa de reza kaiowa tem grandes dimensões, medindo de 12 a 15 metros de largura e com um comprimento entre 30 a 50 metros, com altura em torno de 08 a 10 metros. A base é feita de 
palanques e linhas de aroeira e a cobertura tem uma estrutura de takuavúsu (taquara grande), que vai do chão até a cumieira, e sapé cobrindo toda a estrutura.

Com a depredação ambiental do território de ocupação kaiowa, provocada pela expansão da fronteira agrícola e pelo agronegócio, esses recursos naturais utilizados na construção de uma ogapysy, principalmente o sapé e a taquara já que os palanques foram substituídos por eucalipto, não são encontrados tão facilmente e, nos poucos locais onde ainda se encontra alguns deles, o custo financeiro para obtê-los é alto. Com essa falta de recursos, naturais e financeiros, a construção de uma ogapysy está cada vez mais rara nas aldeias kaiowa.

O cacique Getúlio teve várias casas de reza. Pouco antes do meu primeiro ritual do Batismo do Milho, uma ventania derrubou a sua ogapysy e esse foi o motivo da realização dos ritos no pátio da casa. Com auxílio da FUNASA foi construída outra casa de reza, mas ela durou pouco já que foi incendiada por motivos políticos. Atualmente há uma grande ogapysy que está começando a se deteriorar.

Depois de cumprimentar os anfitriões, comecei a observar tudo ao meu redor, as crianças brincando, os movimentos em direção ao kaguï, a execução das rezas e o revezamento dos yvyraija na condução das mesmas, que nem mesmo as pancadas de chuva deverão atrapalhar, pois esse é um período com muitas chuvas na região.

Quem não está cantando fica em volta observando o andamento dos yvyraija, conversando com os visitantes ou com os outros membros do grupo, dando um gole na chicha, enfim, não há uma regra de comportamento a ser seguido e as conversas e mesmo as risadas altas, que mostram o modo de ser alegre dos kaiowa, não atrapalham o andamento ritualístico.

Foi a partir dessas conversas, embaladas pelas rezas do Batismo do Milho, com o cacique Getúlio e sua esposa Alda que comecei a conhecer o ritual, a sua importância sociocultural. Durante uma conversa com o Getúlio, já depois da meia noite, em um dos intervalos da reza na qual o cacique também participa como yvyraija, soube que as rezas que estavam sendo cantadas, eram preparatórias para alegrar o Jakaira e que o batismo feito pelo ñanderu só iria ocorrer no amanhecer, ou seja, ainda teriam várias horas pela frente e o meu despreparo e cansaço, após mais um dia de trabalho, associado ao sono, me desanimaram e voltei para minha casa em Dourados, abandonando o ritual. Nesse momento, o meu 
desconhecimento do Avati Kyry era tão grande que se quer pensei em uma segunda noite, terminando assim o meu primeiro batismo.

No segundo Batismo do Milho que participei, o meu conhecimento sobre o mesmo já havia ampliado, pelas conversas com o cacique Getúlio e com leituras acadêmicas descritivas do ritual. Nessa minha segunda experiência fui mais preparado e decidido a ficar até o final, o que acabou ocorrendo. Assim como na primeira vez, cheguei ao ritual por volta das $21 \mathrm{~h}$, depois das aulas noturnas do EJA, e fui conduzido pelos anfitriões até a chicha em meio as rezas já iniciadas.

Nesse ano, além da família e dos convidados das aldeias que compõem a RID, estavam presentes integrantes das aldeias Panambizinho, Rancho Jacaré e Sucuri’y.

Da mesma forma já descrita, o processo ritualístico estava ocorrendo, portanto, descreverei a partir de agora a parte relacionada diretamente ao batismo.

Com o amanhecer se aproximando, a irmã do cacique Getúlio foi buscar o ñanderu, que era parente do cacique, um senhor de idade avançada que para se locomover utilizava uma cadeira de rodas. Com a sua chegada iniciou-se o mborahéi puku e algumas mulheres, comandadas por D. Alda, foram à plantação colher as espigas do avati moroti.

Ao retornar da roça, as mulheres colocaram as espigas defronte ao ñanderu que iniciou o batismo. Após a reza, as espigas foram recolhidas e levadas para o preparo de diversos quitutes. Enquanto os quitutes eram preparados, os yvyraija continuaram seus cânticos e assim que os quitutes ficavam prontos, eles eram colocados em frente ao nanderu que os batizava e depois eram distribuídos entre os presentes para serem consumidos.

A essa altura, o sol já tinha nascido e a manhã já se apresentava, os yvyraija com seus mbaraka silenciados juntavam-se aos presentes para o consumo dos quitutes. Esse preparo e consumo dos quitutes ocorreram até por volta das $10 \mathrm{~h}$, quando foi encerrado o ritual.

Na segunda noite, que era um sábado e não houve aula, cheguei cedo, antes do anoitecer e pude presenciar o início do Jerosy Puku. Com os mbaraka e takuapu em repouso no altar, o kotyhu e o guahu envolveram os presentes numa alegria contagiosa. Nessa noite dancei muito e, por volta das $2 \mathrm{~h}$ voltei para casa, onde me entreguei a um sono profundo e relaxante, encerrando o meu segundo Avati Kyry.

Nesse mesmo ano, a família extensa do cacique Getúlio sofreu uma grande perda com a morte do ñanderu. Com essa morte um grande questionamento me ocorreu: quem irá batizar o milho no próximo Avati Kyry? 
$\mathrm{Na}$ área de ocupação kaiowa no Brasil, os ñanderu estão cada dia mais raros já que a sua formação, que é especifica para cada ritual, exige um longo processo, que dura vários anos, com o aprendizado de várias rezas, dentre elas o mborahéi puku.

Essa formação dos ñanderu nos dias atuais encontra duas grandes dificuldades. A primeira está relacionada com o ñanderu, os já poucos existentes são idosos e não possuem saúde suficiente para instruir um jovem nos complexos processos ritualísticos. Essa dificuldade foi a responsável pelo fim do Kunumi pepy, o ritual de perfuração do lábio inferior dos meninos, que era praticado na Terra Indígena Panambizinho, localizada no município de Dourados-MS. A instrução exige uma convivência diária entre instrutor e instruído e participações nos rituais durante vários anos. A segunda dificuldade está em encontrar um jovem disposto a enfrentar esse longo aprendizado que consumirá grande parte da sua juventude.

A superação dessas dificuldades é o grande desafio a ser enfrentado pela etnia kaiowa já que sem o ñanderu para realizar a reza longa, o ritual do Batismo do Milho está fadado a desaparecer para sempre, causando um desequilíbrio cósmico de proporções incalculáveis pela lógica kaiowa.

Esses conhecimentos sobre a formação dos ñanderu me foram passados pela professora Edna de Souza, filha do grande líder guarani Marçal de Souza e grande conhecedora da cultura guarani, em nossas conversas sobre as dificuldades para se manter os rituais nos dias atuais.

Com o período de realização do Batismo do Milho se aproximando, questionei o cacique Getúlio quem seria o ñanderu e como resposta ele disse que iria convidar um de outra aldeia. Sabendo que nesse momento são poucos os rezadores do milho em atividade e com o desejo de conhecer outro rezador, me preparei para participar mais uma vez do ritual.

Com o intuito de participar desde o começo do processo ritualístico e de conhecer o "novo" ñanderu, consegui um substituto para as aulas e cheguei ao entardecer na casa de Getúlio. Para minha decepção o ñanderu ainda não havia chegado e com o anoitecer se revelando, deu-se início ao ritual com os yvyraija cantando e dançando.

Com o avançar das horas, perguntei para Getúlio sobre o ñanderu e ele respondeu somente que estava para chegar, enquanto isso o processo ritualístico seguia com seus cânticos, danças e consumo da chicha. 
O amanhecer já se aproximava e o ñanderu não chegava. Por volta das 4 h, cansado e já descrente na vinda do rezador, me despedi dos presentes e voltei para casa.

No dia seguinte, a minha ansiedade e curiosidade pela conclusão do ritual era enorme, porém foi necessário ser contida já que de nada adiantaria ir logo cedo para a reserva, pois, depois de uma longa noite todos estariam descansando e acabaria "perdendo a viagem".

No meio da tarde, me dirigi a casa do cacique Getúlio e depois dos cumprimentos iniciais perguntei ao mesmo se o ñanderu havia comparecido e tive como resposta o relato de um fato por mim inesperado.

O ñanderu não veio, mas o grupo familiar resolveu ir atrás do ñanderu Luí, morador da Terra Indígena Panambizinho. Segundo o relato do cacique Getúlio, como o processo ritualístico tinha se iniciado e Jakaira chamado, o mesmo não poderia ser interrompido e como solução foi fazer a colheita do milho, colocar os familiares na carreta do trator e todos se dirigiram à casa do nãnderu Luí, distante uns trinta quilômetros da RID, para concluir o ritual, o que acabou acontecendo.

Com a primeira noite concluída, apesar dos percalços, com sucesso, o Jerosy Puku se realizou e todos puderam se divertir com o guahu e com a chicha, expressando a alegria de mais um Avati Kyry realizado para satisfação de Jakaira e manutenção do equilíbrio cósmico.

Com uma maior familiaridade, tanto com o ritual como com a família extensa liderada pelo cacique Getúlio, a minha quarta participação no Batismo do Milho foi a mais completa, uma vez que pude me envolver desde a preparação do ritual.

Nesse ano, o cacique Getúlio conseguiu, com auxílio da FUNASA, construir uma ogapysy (casa de reza), da qual tive a oportunidade de acompanhar a sua construção. A construção da ogapysy deu mais alegria e disposição ao grupo familiar para a realização do Batismo do Milho.

Já na preparação do solo e no plantio do milho saboró era perceptível a animação dos membros do grupo familiar e a alegria estava estampada na face de todos.

Como é comum entre os kaiowa, as rezas foram executadas durante o plantio e diariamente durante o desenvolvimento da plantação, sendo que nas sextas-feiras e nos sábados os cânticos e as danças iam até alta madrugada. Essas rezas não exigem a presença do ñanderu, mas em alguns finais de semana ele veio participar, uma vez que a partir daquele episódio passado, o ñanderu Luí passou a ser o rezador do Avati Kyry realizado pela família do cacique Getúlio. 
$\mathrm{O}$ ritual realizado neste ano foi o maior, em termos de convidados, que participei. $\mathrm{O}$ cacique Getúlio contou com uma grande colaboração, em alimentos, transporte de pessoas, entre outros, da FUNASA e da FUNAI, reunindo representantes de várias aldeias kaiowa, já que os mesmos tinham interesse em realizar discussões, durante o dia, de outros assuntos indígenas e aproveitaram a realização do ritual para reunir as lideranças/representantes, aproveitando para resolver os dois assuntos.

Na semana que antecedeu o ritual, a movimentação e preparação do mesmo foi grande, tendo até a construção de abrigos provisórios para os convidados. Já na quinta-feira os mesmos começaram a chegar, uma vez que na sexta-feira à tarde estava prevista uma reunião com a FUNAI. Desta forma, o final de semana teve durante os dias reuniões e nas noites o Avati Kyry, sendo que no domingo depois do almoço, todos os convidados retornaram às aldeias de origem.

Na primeira noite do ritual todos estavam alegres e muito animados. Ao contrário dos anos anteriores, onde o ritual era realizado no pátio da casa a céu aberto e sujeito as intempéries, todo o processo ritualístico ocorreu dentro da ogapysy, ficando a parte externa da mesma para descanso e conversas entre os participantes.

Dentro da casa de reza, o ambiente era mágico e encoberto por uma bruma, misturada por fumaça e poeira, produzida pelo bater dos pés e do takuapu no chão de terra batida.

As reuniões e as duas noites do ritual transcorreram sem nenhuma intercorrência e foram um sucesso, regado a muita chicha, muitas rezas e, como é comum entre os kaiowa, muita alegria com gargalhadas aqui e ali. Com Jakaira satisfeito e retornando aos patamares celestiais, o ritual se encerrou, deixando em todos a esperança de sua realização na próxima colheita do avati moroti.

Nos demais Batismos do Milho que participei não percebi qualquer outra alteração/percepção, em relação a preparação e ao ritual, que me chamou a atenção. Apesar de não frequentar nenhum outro Avati Kyry, há uns cinco anos, sei que o mesmo continua sendo realizado, todos os anos, na colheita de verão e a família extensa liderada pelo cacique Getúlio já plantou o avati morotï e as rezas já começaram prevendo que mais uma vez, no período das chuvas que se aproxima, os seus membros terão motivos de sobra para cantar e dançar para Jakaira.

\section{CONSIDERAÇÕES FINAIS}




\section{Nanduty}

Como foi visto, a manutenção e realização do Avati Kyry, pela família extensa liderada pelo cacique Getúlio e sua esposa Alda, exige grandes esforços e uma grande superação das dificuldades pelo grupo.

A falta de recursos naturais e financeiros, associada a desestruturação cultural, principalmente em relação a formação dos ñanderu, se mostram como principais empecilhos para a conservação desse importante ritual kaiowa. Porém, esses não são os únicos empecilhos. Nos últimos anos tem se acirrado o conflito, entre os Kaiowa e o agronegócio, pela posse e ampliação do território de ocupação dessa etnia.

O processo histórico e as políticas integracionistas concentraram os diversos grupos kaiowa em pequenas reservas, inviabilizando a manutenção cultural e social tradicional dessa etnia, fazendo com que o Avati Kyry seja o único ritual ainda praticado em algumas áreas, mostrando a força e a resistência cultural dos kaiowa.

Todavia, essa resistência cultural está prestes a sofrer um novo e duro golpe. A eleição presidencial, realizada nesse ano de 2018, teve como vencedor o candidato da extrema direita e o seu discurso, em relação as questões indígenas, prevê a volta da política integracionista, a repressão das retomadas dos territórios tradicionais e a valorização do agronegócio, prevendo momentos terríveis as culturas tradicionais indígenas a partir de 2019, com um futuro cada vez mais incerto para as mesmas.

Mesmo com essas previsões de dias tenebrosos, o cacique Getúlio e seus liderados já plantaram o milho saboró e as rezas de sua sustentação e boa produção já estão a "todo vapor”, prevendo a realização de mais um Avati Kyry com muita dança, cantos e alegria. 


\section{REFERÊNCIAS BIBLIOGRÁFICAS}

ASSIS, Cecy Fernandes de. 2000. Ñe’ë Ryru Avañ’ë. Edição Própria: São Paulo-SP.

BALLARINI, Arnaldo José; SANTOS, Rodrigo Martins dos; SOUZA, Kenedy Moraes. 2012. A importância do Avatí Kyry (Batismo do Milho Branco) para a Saúde do Povo Guarani (Ñandeva e Kayowá) da Reserva Indígena de Dourados. VI Encontro Nacional da Anppas, 18 a 21 de setembro de 2012, Belém - PA.

BRAND, Antonio. 1993. O confinamento e seu impacto sobre os Pai/Kaiowá. $158 \mathrm{f}$. Dissertação (Mestrado em História) - Pontifície Universidade Católica, Rio Grande do Sul.

1997. O impacto da perda da terra sobre a tradição Kaiowá/Guarani: os difíceis caminhos das Palavras. 365 f. Tese (Doutorado em História) - Pontifície Universidade Católica, Rio Grande do Sul.

GARCIA, Wilson Galhego. 2001. Nande Rembypy: Nossas Origens. Araraquara: UNESPFaculdade de Ciências e Letras. Centro de Estudos Indígenas "Miguel A. Menéndez".

MURA, Fábio. 2006. À procura do "bom viver": Território, tradição de conhecimento e ecologia doméstica entre os Kaiowa. Tese de Doutorado em Antropologia Social. Rio de Janeiro: UFRJ-Museu Nacional.

OLIVEIRA, Roberto Cardoso. 2000. O Trabalho do Antropólogo. 2. ed. Brasília: Paralelo/São Paulo: Editora UNESP.

RIBEIRO, Darcy. 1989. Os Índios e a Civilização. São Paulo: Círculo do Livro S.A.

VIETTA, Katya. 2007. Histórias sobre terras e xamãs kaiowá: territorialidade e organização social na perspectiva dos Kaiowá de Panambizinho (Dourados, MS) após 170 anos de exploração e povoamento não indígena da faixa de fronteira entre o Brasil e o Paraguai. São Paulo, USP. 